\title{
Corrections
}

\section{Correction: Sim et al., Increased Cell-Intrinsic Excitability Induces Synaptic Changes in New Neurons in the Adult Dentate Gyrus That Require Npas4}

In the article "Increased Cell-Intrinsic Excitability Induces Synaptic Changes in New Neurons in the Adult Dentate Gyrus That Require Npas4" by Shuyin Sim, Salome Antolin, Chia-Wei Lin, Ying-Xi Lin, and Carlos Lois, which appeared on pages $7928-7940$ of the May 1, 2013 issue, the authors regret misspelling the fourth author's first name. The corrected author line is as follows: Shuyin Sim, Salome Antolin, Chia-Wei Lin, Yingxi Lin, and Carlos Lois. Also, not all the funding sources were cited in the accepted version of the Acknowledgments. The corrected list of funders is as follows: This work was supported by a NIDCD RO1 Grant to C.L. and funded in part with a grant from the MIT Simons Initiative on Autism and the Brain (Y.L. and C.L.). These corrections have been corrected on the online PDF version.

DOI:10.1523/JNEUROSCI.2228-13.2013

\section{Correction: Kundu et al., Strengthened Effective Connectivity Underlies Transfer of Working Memory Training to Tests of Short-Term Memory and Attention}

In the article "Strengthened Effective Connectivity Underlies Transfer of Working Memory Training to Tests of Short-Term Memory and Attention" by Bornali Kundu, David W. Sutterer, Stephen M. Emrich, and Bradley R. Postle, which appeared on pages 8705-8715 of the May 15, 2013 issue, there were two errors. In Figure 1, for panels $A, D$, and $E$, the targets were each presented for $200 \mathrm{~ms}$ and the interstimulus interval duration was $400 \mathrm{~ms}$ (incorrectly reversed in the figure). For Table 1, the ANOVA results shown on the second line correspond to analysis of the task reaction times presented on lines 3 and 4 (Load 2 RT and Load 4 RT). These corrections do not affect any of the conclusions in the paper.

DOI:10.1523/JNEUROSCI.2231-13.2013 